\title{
Postpartum Severe Acute Maternal Morbidity According to Gestational Age at Delivery in Twin Pregnancies: A Prospective Cohort Study
}

Lola Loussert ${ }^{1}$, Catherine Deneux-Tharaux ${ }^{1}$, Aurélien $\mathrm{Seco}^{2}$, Francois Goffinet ${ }^{3}$, diane korb $^{1}$, and Thomas Schmitz ${ }^{1}$

${ }^{1}$ Université de Paris, Centre for Research in Epidemiology and Statistics (CRESS), Obstetrical Perinatal and Pediatric Epidemiology Research Team - INSERM U1153

${ }^{2}$ Clinical Research Unit Necker Cochin, APHP

${ }^{3}$ Université de Paris, Centre for Research in Epidemiology and Statistics (CRESS), Obstetrical Perinatal and Pediatric Epidemiology Research Team - INSERM U1153

October 25, 2021

\begin{abstract}
Objective: To assess the association between gestational age at delivery and postpartum severe acute maternal morbidity (SAMM) in twin pregnancies. Design: Population-based, national, prospective, cohort study Setting: From 02/2014 to 03/2015 in France Population: Women with twin pregnancies who gave birth after 32 weeks of gestation. We excluded women with fetal death or medical termination of either twin, with antepartum SAMM, with antepartum conditions responsible for postpartum SAMM. Methods: Gestational age at delivery was studied as the number of completed weeks of gestation. We assessed the association between gestational age at delivery and postpartum SAMM by using multivariable multilevel modified Poisson regression modelling. Main Outcome Measures: Composite criteria of postpartum severe acute maternal morbidity Results: Among the 7,713 women included, 410 (5.3\%) developed postpartum SAMM, mainly (88.5\%) postpartum haemorrhage. Compared with the reference category of 37 weeks, the risk of postpartum SAMM was significantly lower for all categories of earlier gestational age at delivery (from $\mathrm{aRR}=0.34,95 \% \mathrm{CI} 0.17-0.68$ at 32 weeks to $\mathrm{aRR}=0.71,95 \%$ CI 0.54-0.94 at 36 weeks), and did not differ for later categories. Conclusion: In twin pregnancies, compared with delivery at 37 weeks, delivery at earlier gestational ages is associated with a lower risk of postpartum SAMM. Continuing pregnancy beyond 37 weeks is not associated with an increased risk of postpartum SAMM. Funding: Supported by a grant from the French Ministry of Health (Programme Hospitalier de Recherche Clinique, AOM2012) and a grant from Université Toulouse III. Keywords: severe acute maternal morbidity, twin pregnancy, timing of delivery
\end{abstract}

\section{Hosted file}

Main Document.docx available at https://authorea.com/users/417346/articles/543033-postpartumsevere-acute-maternal-morbidity-according-to-gestational-age-at-delivery-in-twinpregnancies-a-prospective-cohort-study

\section{Hosted file}

Figure 1.docx available at https://authorea.com/users/417346/articles/543033-postpartumsevere-acute-maternal-morbidity-according-to-gestational-age-at-delivery-in-twinpregnancies-a-prospective-cohort-study

\section{Hosted file}


Figure 2.docx available at https://authorea.com/users/417346/articles/543033-postpartumsevere-acute-maternal-morbidity-according-to-gestational-age-at-delivery-in-twinpregnancies-a-prospective-cohort-study 